\title{
A PROSPECTIVE STUDY OF MATERNAL AND PERINATAL OUTCOME IN MULTIFETAL GESTATION IN RURAL INDIA
}

\author{
Sheela. S. R, Lakshmikantha. G, Shivaleela Angadi
}

1. Professor, Department of Obstetrics \& Gynaecology, Sri Devaraj Urs Medical College, Tamaka, Kolar, Karnataka, India.

2. Assistant Professor, Department of Obstetrics \& Gynaecology, Sri Devaraj Urs Medical College, Tamaka, Kolar, Karnataka, India.

3. Resident, Department of Obstetrics \& Gynaecology, Sri Devaraj Urs Medical College, Tamaka, Kolar, Karnataka, India.

\section{CORRESPONDING AUTHOR}

Dr. Lakshmikantha G, \#249, 3rd A main,

Near Amba Bhavani Circle,

NE of NR Mohalla, Mysore, Karnataka, India.

E-mail: drlakshmikanthag@yahoo.co.in

Ph: 00919740810611

CAPSULE: Multifetal gestation has maternal and perinatal adverse effects. These can be prevented by proper antenatal care, prolonging the gestation as far as possible till fetal lung maturity is attained, early admission and management in a tertiary health care.

KEY WORDS: Multifetal gestation, Preterm, maternal mortality, perinatal mortality

ABSTRACT: OBJECTIVES: To study the maternal and fetal outcome in multifetal gestation in a rural area. METHODS: A prospective study of 50 consecutive cases of multifetal gestation was conducted between October 2007 to July 2010.Incidence of relevant factors, complications characteristic for multifetal gestation and the sequelae of these complications on maternal and fetal outcome were analysed. RESULT: Incidence of multifetal gestation was $2 \%$, anemia $22 \%$, preterm labour in $62 \%$, severe pre-eclampsia in $34 \%$, postpartum hemorrhage in $16 \%$, PPROM in $14 \%$, abortion in $8 \%$, eclampsia in $2 \%$. Incidence of perinatal mortality rate was 240 per 1000live births and maternal mortality was 2000/1 lakh live births which was 10 times more compared to singleton pregnancy. CONCLUSION: Regular antenatal care ,prolonging period of gestation near to term, early admission and care will go long way in reducing maternal and perinatal mortality.

INTRODUCTION: The incidence of twinning and higher order multiple pregnancies has increased dramatically over the last two decades and the greatest contributor to this explosion in multiple gestations has been delayed fertility and the use of assisted reproductive technologies. Multiple gestation having increased placental and fetal mass is likely to have increased physiologic responses compared with singleton pregnancies. These exaggerated physiologic changes and mechanical stress in multiple pregnancies could be associated with an increase in adverse maternal outcomes such as pulmonary oedema due to decreased cardiac reserve, venous thromboembolic disease and even death [1]. Complications of pregnancy like pregnancy induced hypertension, gestational diabetes, anaemia, abortions, malpresentations, antepartum haemorrhage, UTI, varicosities, haemorrhoids could be more frequent and more severe in multifetal gestation compared to singleton pregnancy. This could be due to exaggerated physiological changes, excess mechanical stress, which could lead to increased 
obstetrical intervention, increased morbidity and mortality[2,3]. Multiple pregnancy due to over distension of uterus could have a higher rate of premature delivery than singleton pregnancies and a substantially higher perinatal morbidity and mortality[4].

Moreover, the potential for fetal growth restriction is increased in multifetal gestation due to an increase in fetal metabolic demands, placental and cord anomalies, increased incidence of maternal complications and increased fetal crowding[5].There is theoretical risk that a significant reduction in uterine volume following delivery of first fetus, that might precipitate partial placental separation and reduction in uterine perfusion and placental circulation, thus jeopardising the subsequent foetuses, with increase in perinatal morbidity and mortality. So, multiple pregnancy is a high risk pregnancy which could adversely affect both mother and fetus. Moreover, delivery of multiple foetuses may present psychologic, social and economic problems [6].

METHODOLOGY: A prospective observational study was performed on 50 women with multiple gestation who attended our department between Oct 2007 and July 2010. Pregnant women with pre-existing medical disorder that would likely increase their risk of pregnancy complications (i.e., pre-existing hypertension, pregestational diabetes, cardiac disorder , renal disease or collagen vascular disease etc.) were excluded from this study. Informed consent and ethical committee approval was obtained. Study was done during antenatal, labour and postnatal period till the patients were discharged. Detailed obstetrics history was taken including family history and history of intake of ovulation induction drugs and infertility treatment.

Examination was done to note any associated medical or obstetric complications .If first twin was longitudinal and no obstetric indication for caesarean section, vaginal delivery was allowed. After delivery of the first twin the presentation, position, size and its relation to birth canal was quickly assessed. . If the second twin was longitudinal, if no haemorrhage and fetal distress, waited for spontaneous resumption of contractions for about 10 minutes. Oxytocin augmentation was begun if contractions decrease.ARM was done after fixing the presenting part.FHS was regularly monitored. Interference was done with forceps or vacuum if the second stage was prolonged. In breech presentation with an adequate maternal pelvis, average fetal size, good uterine contractions and a completely dilated and effaced cervix, assisted beech delivery was conducted. If second twin was transverse it was corrected by external version into a longitudinal lie to vertex or breech presentation. If external version fails or membranes rupture, internal podalic version is done under general anaesthesia followed by breech extraction. After delivery of babies APGAR score was evaluated. Active management of $3^{\text {rd }}$ stage was done by prophylactic uterotonics to reduce postpartum haemorrhage. Placental examination was done to study the chorionicity and zygosity. Postpartum endometritis, DVT, neonatal complications, if any, are noted.

RESULTS: Incidence of multifetal gestation was $2 \%$, anemia $22 \%$, preterm labour $(<37$ completed weeks) in $62 \%$, severe pre-eclampsia in $34 \%$, postpartum hemorrhage in $16 \%$, PPROM in $14 \%$, abortion in $8 \%$, eclampsia in $2 \%$. Seventy percent of patients belonged to age group between 20 and 30 yrs. $52 \%$ multigravida, $48 \%$ primigravida. Family history of multiple gestation was present only in $26 \%$ cases. $88 \%$ had conceived spontaneously and $12 \%$ after assisted reproductive techniques (ART). Table 1 shows various antepartum complications seen in our study. In the present study maternal mortality was due to acute renal failure secondary to eclampsia. 
Caesarean section rate was 34\%. Postpartum hemorrhage in $16 \%$ of patients and all of them were controlled with medical line of management.

In the present study 17 (34\%) of cases were dichorionic- diamniotic, 8 (16\%) of cases were Monochorionic-diamniotic, 24 ((48\%) of cases were monochorionic- monoamniotic. $25(27.17 \%)$ of cases needed NICU admission in both first and second twin. The various reasons for NICU admission were LBW, preterm birth, IUGR and birth asphyxia.

$12(24 \%)$ perinatal deaths occurred in the study giving a perinatal mortality rate (PMR) of $240 / 1000$ live births. Perinatal mortality rate was $6(12 \%)$ for first fetus, $6(12 \%)$ for second fetus. There was no perinatal death for foetuses weighing more than $2500 \mathrm{gms}$ in any of the foetuses. Perinatal mortality rate was $100 \%$ if gestational age was less than 28 weeks.

DISCUSSION : The incidence of multifetal gestation has been increased dramatically over last two decades. The greatest contributor for this explosion is delayed fertility and use of assisted reproductive technology. Multiple pregnancy is a high risk pregnancy. It has got more complications for both mother and the babies when compared with singleton pregnancy. Thus multifetal gestation needs more regular antenatal checkups, institutional care and delivery than singleton pregnancy. Preterm labour is the most common complication among all other complications in multifetal gestation. It is the leading cause of increased perinatal mortality in multifetal gestation .So all efforts must be taken to prolong pregnancy. Risks of multiple pregnancy should be explained clearly to all mothers with multiple pregnancy. Majority of the complications can be prevented with intensive approach and protocols during antenatal period and labour, especially for correction of anaemia, treatment of infections and early admission in the presence of threatened preterm labour and thus arresting preterm labour. Adequate tocolysis should be instituted till lung maturity of fetus is achieved either artificially or naturally. Lung maturity should be achieved by administering steroids at right time thus preventing perinatal mortality secondary to preterm birth. Accelerated maturity of multiple gestation was evident in present study as most of the low birth weight babies survived without the need for NICU care. Perinatal mortality was almost similar for either of the twins for that period of gestation and birth weight. Thus suggesting that period of gestation and birth weight was an important factor for the good perinatal outcome. High rate of perinatal mortality can be reduced by decreasing the incidence of low birth weight infants rather than increasing the rate of caesarean sections and by regular antenatal check-ups, early detection and prevention of preterm labour.

CONCLUSION: Perinatal mortality can be prevented by optimum care of mother and fetus in antenatal period, prolonging the duration of gestational age as far as possible till fetal lung maturity is attained. Both maternal and perinatal mortality can also be reduced by appropriate management protocols directed towards counseling, regular antenatal checkups, proper care during intrapartum and postpartum period and early admission of mothers to prevent complications. However studies involving large number of cases are required to support these findings.

CONFLICT OF INTEREST: None to disclose 


\section{REFERENCES:}

1. Mark C. Walker, Kellie E. Murphy, Saiyi Pan, Qiuying Yang, Shi Wu Wen. "Adverse maternal outcomes in multifetal pregnancies “. Br J ObstetGynaecol 2004;111:1294-1296.

2. Cynthia Gyamfi, MD, Joanne Stone, MD, Keith A. Eddleman, MD. "Maternal Complications of Multifetal Pregnancy". Clin Perinatal 2005;32:431-442.

3. Misty C. Day, MD, John R. Barton, MD, John M. O’Brien, MD, NikinB. Istwan, RN, and Baha M. Sibai, MD."The effect of fetal number on the development of hypertensive conditions of pregnancy". ObstetGynecol 2005;106:927-31.

4. Michael O. Gardner, Robert L. Goldenberg, Suzanne liver, et al "The origin and outcome of preterm twin pregnancies.”ObstetGynaecol 1995; 85(4): 553-557.

5. Emily F. Hamilton, Robert W. Platt, Lucie Morin et al., "How small is too small in a twin pregnancies?"Am J ObstetGynaecol 1996; 179: 682-685.

6. G. Holcberg, MD, Y. Biale, PhD, MD, H. Lewenthal, MD, and V. Insler, MD. "Outcome of Pregnancy in 31 Triplet Gestations" ObstetGynaecol 1982;59(4):472-476.

7. Barbara Luke, ScD, MPH, RD. "The Changing Patterns of Multiple Births in the United States: Maternal and Infant Characteristics, 1973 and 1990". ObstetGynaecol 1994;84:101-106.

8. KushlaPathania, Advitendra Singh, KumudBala Gupta, H.K. Premi, Rajeev Sood. “Outcome of Triplet Gestations in an Apex Institution". J ObstetGynecolInd 2001;51:108-110.

9. D. Itzkowic. Queen Charlotte's Maternity Hospital, London."A survey of 59 triplet pregnancies “ Br J ObstetGynaecol 1979;86;23-28.

TABLES: Table no.I : Antepartum complication in multifetal gestation and its incidence, the commonest complication being preterm labour.

\begin{tabular}{|l|l|l|}
\hline complication & No of cases & Percentage \\
\hline Abortion & 4 & 8 \\
\hline Preterm labour(<37 weeks) & 31 & 62 \\
\hline Severe pre-eclampsia & 17 & 34 \\
\hline Anaemia & 11 & 22 \\
\hline Antepartum haemorrhage & 1 & 2 \\
\hline PPROM & 7 & 14 \\
\hline Eclampsia & 1 & 2 \\
\hline Renal failure & 1 & 2 \\
\hline Maternal mortality & 1 & 2 \\
\hline
\end{tabular}

Abbreviations: PPROM- preterm premature rupture of membranes. 
Table no. II : Combination of presentations in multifetal gestation, the commonest being both vertex presentation.

\begin{tabular}{|c|c|c|}
\hline $\begin{array}{c}\text { COMBINATION OF } \\
\text { PRESENTATION }\end{array}$ & $\begin{array}{c}\text { No of } \\
\text { case }\end{array}$ & $\%$ \\
\hline Vertex+ Vertex & 17 & 34 \\
\hline & & \\
\hline vertex+ Breech & 11 & 22 \\
\hline Breech + Vertex & 3 & 6 \\
\hline Vertex + transverse & 7 & 14 \\
\hline Breech + Breech & 3 & 6 \\
\hline Transverse+ Breech & 2 & 4 \\
\hline Transverse+ Transverse & 2 & 4 \\
\hline Breech + Transverse & 1 & 2 \\
\hline Variable & 4 & 8 \\
& 50 & 100 \\
\hline
\end{tabular}

Table no. III : Comparative analysis of preterm labour

\begin{tabular}{|l|l|l|}
\hline Authors & Year & Incidence\% \\
\hline Holceberg & & \\
\hline Barbara Luke $^{7}$ & 1982 & 97 \\
\hline Khushla Pathania $^{8}$ & 2001 & 60 \\
\hline Itzkowic $^{9}$ & 1979 & 78 \\
\hline Present study & & $\mathbf{6 2}$ \\
\hline
\end{tabular}

Table no. IV: perinatal mortality in relation to birth weight showing better outcome for babies with more birth weight.

\begin{tabular}{|l|l|l|l|l|}
\hline $\begin{array}{l}\text { Birth } \\
\text { weight(grams) }\end{array}$ & $\begin{array}{l}\text { First fetus } \\
(\mathrm{n}=50)\end{array}$ & $\begin{array}{l}\text { Second } \\
\text { fetus } \\
(\mathrm{n}=50)\end{array}$ & \\
\hline & $\begin{array}{l}\text { No. of } \\
\text { cases }\end{array}$ & $\begin{array}{l}\text { No. of } \\
\text { babies died }\end{array}$ & No. of cases & $\begin{array}{l}\text { No. of } \\
\text { babies died }\end{array}$ \\
\hline $1050-1500$ & 13 & 4 & 16 & 4 \\
\hline $1550-2000$ & 18 & 1 & 16 & 1 \\
\hline $2050-2500$ & 16 & 1 & 14 & 1 \\
\hline$>2500$ & 3 & - & 4 & - \\
\hline
\end{tabular}


Table no. $V$ : Various causes for perinatal mortality in the present study, the commonest being preterm birth.

\begin{tabular}{|l|l|l|}
\hline Causes & No. of cases & $\begin{array}{l}\text { No. of perinatal } \\
\text { deaths }\end{array}$ \\
\hline Preterm (<37 weeks) & 62 & 7 \\
\hline IUGR & 8 & 1 \\
\hline Aspiration syndrome & 1 & 1 \\
\hline Colloidon syndrome & 1 & 1 \\
\hline $\begin{array}{l}\text { Maternal renal failure } \\
\text { sec. to antepartum } \\
\text { eclampia causing } \\
\text { hypoxia }\end{array}$ & 1 & 2 \\
\hline
\end{tabular}

Table no. VI : Influence of gestational age on perinatal mortality .

\begin{tabular}{|l|l|l|l|l|l|l|l|}
\hline \multicolumn{5}{|c|}{1 stfetus(n=50) } & \multicolumn{5}{c|}{} \\
\hline $\begin{array}{l}\text { Gestational } \\
\text { age(weeks) }\end{array}$ & $\begin{array}{l}\text { No of } \\
\text { cases }\end{array}$ & $\begin{array}{l}\text { No of } \\
\text { deaths }\end{array}$ & $\%$ & $\begin{array}{l}\text { Gestational } \\
\text { age (weeks) }\end{array}$ & $\begin{array}{l}\text { No of } \\
\text { cases }\end{array}$ & $\begin{array}{l}\text { No of } \\
\text { deaths }\end{array}$ & $\%$ \\
\hline$<28$ & 4 & 4 & $100 \%$ & $<28$ & 4 & 4 & $100 \%$ \\
\hline $28-37$ & 4 & 2 & $50 \%$ & $28-37$ & 4 & 2 & $50 \%$ \\
\hline $\begin{array}{l}37 \text { and } \\
\text { above }\end{array}$ & 16 & 0 & $0 \%$ & $\begin{array}{l}37 \text { and } \\
\text { above }\end{array}$ & 16 & 0 & $0 \%$ \\
\hline
\end{tabular}

